\title{
AVALIAÇÃO DA ILUMINAÇÃO ARTIFICIAL EM SALAS DE AULAS EM UMA ESCOLA DA REDE DE ENSINO PUBLICA DE NOVA VENÉCIA-ES
}

Tereza Cristina de Souza Ayres ${ }^{1 *}$ Raphael Melo Borges ${ }^{1}$ Águida Silva Bullerjahn² Daniel Silva Souza ${ }^{2}$ Gabriel Balbino dos Santos ${ }^{3}$ Hiago Fernando Vagmaker Gonçalves ${ }^{4}$ Layla Teixeira Viana ${ }^{5}$

\section{RESUMO}

A iluminação adequada em ambientes escolares é fator importante para a saúde e o bom rendimento de alunos. Este artigo apresenta os resultados de uma pesquisa que avalia a iluminação artificial das salas de aula de uma escola da Rede Pública de ensino na cidade de Nova Venécia - ES, verificando sua adequação às normas vigentes de luminotécnica (ABNT NBR ISSO/CIE 8995-1:2013). A metodologia inclui realização de medições in loco com luxímetro digital e aplicação do método dos lumens. Os resultados obtidos permitem afirmar que nenhuma das 13 salas de aula analisadas está adequada para atividades de ensino noturno. Apesar da normatização, e já ter sido comprovada a importância da iluminação no ambiente escolar, a pesquisa demonstra que o problema ainda persiste nesta escola pública.

Palavras-chave: Iluminação escolar, Conforto ambiental, Conforto visual, iluminância.

\footnotetext{
${ }^{1}$ Instituto Federal do Espírito Santo, Ifes Campus Nova Venécia, Nova Venécia-ES.

${ }^{2}$ Universidade Federal de Viçosa, Departamento de Engenharia de Produção, Viçosa-MG.

${ }^{3}$ Universidade Federal de Viçosa, Departamento de Engenharia de Civil, Viçosa-MG.

${ }^{4}$ Universidade Federal do Espirito Santo, Departamento de Engenharia de Civil, Vitória-ES.

${ }^{5}$ Universidade Federal de Viçosa, Viçosa-MG.

*Autor para correspondência: tereza.ayres@ifes.edu.br
} 


\title{
EVALUATION OF ARTIFICIAL ILLUMINATION IN CLASSROOMS IN A SCHOOL OF THE PUBLIC EDUCATION NETWORK OF NOVA VENÉCIA-ES
}

\begin{abstract}
Adequate lighting in school environments is an important factor for the health and good performance of students. This article presents the results of a research that evaluates the artificial illumination of the classrooms of a School of Public School System in the city of Nova Venécia - ES, verifying its adequacy to the current standards of lighting technology (ABNT NBR ISSO/CIE 8995-1:2013). The methodology includes realization of measurements in loco with digital luximeter and application of the lumens method. The results obtained allow us to state that none of the 13 classrooms analyzed is suitable for night teaching activities. Despite the normalization, and already been proven the importance of lighting in the school environment, research shows that the problem still persists in this public school.
\end{abstract}

Keywords: School lighting, Environmental comfort, Visual comfort, illuminance.

\section{INTRODUÇÃO}

O Conforto Ambiental é uma área de estudo que tem por objetivo projetar edificações considerando as relações do usuário com o ambiente projetado e as condições ambientais de tal forma que se garanta ao ser humano bem-estar térmico, visual, acústico, olfativo e antropométrico. O conforto visual se aplica ao estudo das condições de iluminação natural e artificial para desempenho de diferentes atividades humanas. Cada atividade necessita de diferente acuidade visual e a adequação da iluminação diminui riscos à saúde e riscos de acidentes.

A luz de um ambiente influi diretamente na produtividade, no desempenho, na percepção de espaço e na qualidade de vida dos que o utilizam. Em ambientes de trabalho e estudos há a necessidade de mensurar-se a quantidade de iluminação disponível, pois em quantidades baixas ou em excesso, as atividades a serem desenvolvidas podem ser comprometidas. Normas regulamentadoras estabelecem valores médios de luminância e iluminância característicos de cada tipo de ambiente, levando-se em consideração seu uso.

Em ambientes escolares, a relação entre a iluminação e seus usuários se torna mais intensa. Estudos mostram que o desempenho escolar do aluno está diretamente relacionado com a qualidade da iluminação em sala de aula (BARRET, 2015 apud HYBNER, 2015). Sabe-se que a falta de iluminação adequada em escolas, pode originar situações de desconforto e mal-estar, como dores de cabeça e desânimo, podendo até mesmo afetar no 
desenvolvimento do indivíduo (KÜLLER; LINDSTEIN, 1992 apud HYBNER, 2015). O papel da visão está relacionado diretamente com a curiosidade e é através da visão que surgem os estímulos para novas descobertas. Por isso, em um ambiente escolar um bom projeto luminotécnico é de extrema relevância.

O projeto de luminotécnica não é obrigatório para a maioria das prefeituras. Ao longo do tempo muitas escolas foram construídas sem uma orientação técnica adequada. Segundo Sátyro e Soares (2007), 90\% das matrículas do ensino fundamental são de escolas públicas e a infraestrutura dos prédios e instalações escolares é capaz de exercer influência significativa sobre a qualidade da educação (SÁTYRO; SOARES, 2007 apud HYBNER, 2015). Aguiar e Bueno-Bartholomei (2014, p 74), afirmam que a qualidade do ensino não é resultante apenas da capacitação dos professores, "mas das características do ambiente, que carece proporcionar espaços agradáveis, assegurando os índices de conforto, e condizentes com as atuais modificações do ensino".

Diante do exposto, o objetivo dessa pesquisa é analisar a adequabilidade da iluminação artificial de uma Escola da Rede de Ensino Pública, localizada no município de Nova Venécia, Espírito Santo, e sua adequação com a norma ABNT NBR ISO/CIE 8995-1:2013 (Iluminação de Ambientes de Trabalho - Parte 1: Interior).

Não é incomum, em cidades de pequeno porte, que obras inteiras sejam feitas sem todos os projetos complementares. Atualmente, a apresentação do projeto de iluminação não é obrigatório para a aprovação de projetos de edificações e obtenção do alvará de construção no município de Nova Venécia.-Neste contexto, a presente pesquisa se mostra pertinente, uma vez que avalia se as práticas atuais possibilitam a utilização dos espaços dentro de parâmetros antropométricos e normativos eficientes.

\subsection{REFERENCIAL TEÓRICO}

Tendo em vista a importância que a iluminação apresenta no processo de ensino aprendizado, é necessário observar todos os aspectos potenciais que uma iluminação adequada pode causar no indivíduo durante esse processo. De acordo com Bertolotti (2007 apud SILVA, 2014, p. 2), entre os muitos fatores que influenciam os processos de aprendizagem, os fatores relacionados com as condições ambientais têm um papel determinante. "O estímulo educacional é repassado através da percepção dos sentidos, sendo um dos mais importantes a visão. Boas condições de iluminação favorecem o desempenho visual, otimizando o processo." A qualidade da luz é também importante para o conforto visual. Os olhos coletam e convertem, através dos nervos óticos, a luz visível em impulsos elétricos direcionados ao cérebro. Uma iluminação de qualidade, além de trazer conforto, otimiza a execução de tarefas, influenciando diretamente no processo de ensino/aprendizagem. 
O Ministério da Educação (MEC) tem divulgado recomendações sobre construções escolares que servem como subsídio para a elaboração de escolas. Tradicionalmente, edificações escolares seguem um Programa de Necessidades previamente estabelecido pelas Secretarias de Educação. A construção de uma unidade de educação demanda planejamento e envolve os estudos de viabilidade, a definição das características ambientais e a elaboração do projeto arquitetônico, incluindo o projeto executivo, o detalhamento técnico e as especificações de materiais e acabamentos (BRASIL, 2006, p. 7).

Em 2002, o MEC, com a ajuda do Fundo de Fortalecimento da Escola (FUNDESCOLA), publicou um manual técnico com o objetivo de dar subsídio para a elaboração de projetos e adequação de qualquer edificação escolar do ensino fundamental no Brasil. Sobre a iluminação artificial, o documento destaca a importância da escolha correta de lâmpadas e luminárias e o combate ao desperdício de energia. O manual recomenda que as lâmpadas e luminárias devem estar de acordo com as normas técnicas, o que contribuirá para redução dos gastos com energia. Na escolha da iluminação adequada para ambientes escolares devem ser observados alguns critérios que proporcionam uma utilização adequada da iluminação, evitando o ofuscamento ${ }^{6}$ e possibilitando a reprodução adequada das cores dos objetos e dos ambientes pedagógicos. Quanto à iluminação o documento se baseou na ABNT NBR 5413:1980, que foi substituída em 2013 pela ABNT NBR ISO/CIE 8995-1:2013

Em 2006 o MEC em parceria com o FUNDESCOLA, o Fundo de Desenvolvimento da Escola (FNDE) e a Diretoria de Programas Especiais (DIPRO), publicou um novo manual. O Manual Para Adequação de Prédios Escolares trouxe um conceito de padronização das salas de aula, especificando serviços e materiais. Segundo este manual "a iluminação deverá ser uniforme em todos os planos de trabalho, obedecendo o parâmetro de iluminância de 300 lux" (BRASIL, 2006, p. 12). Além de especificar uma série de lâmpadas e luminárias a serem usadas em edifícios escolares.

Sendo um dos principais determinantes na realização de atividades visuais, o conforto visual influencia diretamente na produtividade e concentração dos indivíduos. Segundo Barrett (et al., 2015 apud HYBINER, 2015, p. 12), "estudos mostram que o desempenho escolar do aluno está diretamente relacionado com a qualidade da iluminação em sala de aula" Já para Küller e Lindsten (apud HYBINER, 2015, p. 12), o desconforto visual pode trazer consigo sintomas como dores de cabeça, abatimento, podendo até prejudicar o crescimento. Para uma sala de aula, deve ser prevista uma iluminação adequada que permita que os alunos exerçam suas atividades com o máximo de precisão visual e acuidade, dando ao aluno a possibilidade de melhor produtividade sem que este precise se esforçar ou forçar sua visão para isto.

\footnotetext{
${ }^{6}$ Segundo o Aguiar (2011, p. 17), "[...] ofuscamento é o prejuízo na função visual causado pela presença de uma fonte de luz localizada no campo visual $[\ldots .]$.$" .$
} 
Barkmann, Wessolowski e Schulte-Markwort (2012) afirmam que o aumento da iluminação melhora a visão e a capacidade de perceber informações ópticas e que em ambientes com maior iluminância e temperaturas de cor mais frias $(17.000 \mathrm{~K})$ há um efeito estimulante que aumenta os níveis de concentração. E segundo Monteoliva (2016), a atenção é um dos fatores mais importantes na aprendizagem pois facilita o armazenamento e recuperação do conteúdo da memória.

Conforto visual pode ser entendido como a existência de uma série de condições, e segundo a European Commission Directorate (1994 apud DUTRA, et al, 2014, p. 57), os requisitos necessários são: "Iluminância suficiente, boa distribuição de iluminâncias, ausência de ofuscamento, contrastes adequados (proporções de luminâncias) e bom padrão e direção de sombras."

Em situações normais de iluminação, de ofuscamento e foco, o olho humano apresenta condições perfeitas de visualização, o que garante maior percepção dos objetos presentes nos ambientes, e é por esses e outros motivos que uma iluminação adequada é importante em salas de aula. Por outro lado, uma iluminação inadequada pode influenciar negativamente na concentração e na capacidade de aprendizado dos alunos, além de provocar alguns defeitos na visão dependendo do tempo de exposição e da intensidade da iluminação. Segundo Pais (2011, p. 11), "muitas vezes, acontece algo que perturba o funcionamento normal do olho, e que se reflete em alguns defeitos da visão".

Além de causar tais defeitos, que podem ser permanentes ou não, uma má iluminação ou uma iluminação inadequada pode causar alguns desconfortos ou doenças momentâneas, como por exemplo, dor de cabeça. Segundo Veitch (2008 apud PAIS, 2011, p. 13), a iluminação condiciona a percepção e a sensação do trabalhador, causando um desconforto visual, que se traduz em sintomas como a fadiga visual, visão turva, irritabilidade visual, dores de cabeça, dores musculares, stress, dificuldade de concentração. Um dos exemplos citados, a fadiga visual ou astenopatia é uma manifestação de desconforto, dor e irritação visual (PAIS, 2011, p. 14). Outro exemplo de doenças momentâneas são as dores de cabeça, que na maioria das vezes são causadas por iluminação inadequada. Anshel (2005 apud PAIS, 2011, p. 16) informa que as dores de cabeça estão relacionadas com a existência de brilhos, reflexos e iluminação insuficiente.

Um dos fatores que influenciam na qualidade da iluminação é a quantidade de luz, segundo o PROCEL (2011, p. 34):

[...] a quantidade de luz (medida em lux), deve ser orientada especificamente para a superfície que pretendemos ver. Quanto menor for o detalhe, ou mais baixo o contraste, maior quantidade de luz necessitam os nossos olhos para o seu difícil trabalho.

Já uma iluminação inadequada causa um efeito negativo sobre os utilizadores, que podem conduzir suas tarefas de forma ineficiente e perigosa. 
Décadas de investigação científica internacional conduziram ao estudo dos níveis luminosos necessários a várias tarefas específicas. Em locais onde estas recomendações não forem seguidas, a iluminação pode prejudicar o conforto humano, a segurança e produtividade. (PROCEL, 2011, p. 34).

O ofuscamento é outro fator importante para uma boa iluminação. Em pequena escala durante períodos longos de tempo resulta em desconforto que é acompanhado por sensações de fadiga e/ou dor de cabeça (PROCEL, 2011, p. 35). A uniformidade da iluminação se inadequada influencia negativamente na iluminação. Segundo o PROCEL (2011, p. 35), "a distribuição adequada da iluminação é muito importante para evitar sombras acentuadas e assegurar o conforto e a segurança para a prática da atividade exercida na área". O PROCEL (2011, p. 36) esclarece que, "temperatura de cor: é a grandeza que expressa a aparência de cor da luz, sendo sua unidade o Kelvin". Quanto mais alta essa temperatura, mais branca a luz será. A chamada luz quente tem cor amarelada e é considerada de cor baixa, com $300 \mathrm{~K}$ ou menos. Já a luz fria tem cor azul-violeta e é de temperatura elevada, com $6000 \mathrm{~K}$ ou mais. A temperatura da cor está relacionada à fidelidade na reprodução de cores.

Estas características, por serem fatores relevantes para atividades de ensino-aprendizagem estão inseridas nas normas atuais de luminotécnica.

\subsection{NORMAS TÉCNICAS E REGULAMENTADORAS}

Foram utilizadas nessa pesquisa as normas ABNT NBR ISO/CIE 8995-1:2013 (Iluminação de Ambientes de Trabalho - Parte 1: Interior) e ABNT NBR 15215-4:2003 (Iluminação natural - Parte 4: Verificação experimental das condições de iluminação interna de edificações - Método de medição).

\section{METODOLOGIA}

A pesquisa foi dividida em quatro fases. No referencial teórico foi realizada a coleta das informações em normas e outras fontes a fim de levantar o estado da arte quanto ao tema. Na revisão bibliográfica, de modo a descrever os fatos e fenômenos da iluminação artificial em interiores, uma pesquisa de caráter descritivo mostrou-se necessária para o estudo e detalhamento da iluminância e suas propriedades voltadas ao objeto de estudo.

$\mathrm{Na}$ segunda fase foi feito o levantamento físico dos ambientes analisados que se iniciou com a medição das dimensões das salas de aula e de suas características como cor das paredes, cor das cortinas, presença de janelas, de portas, quantidade de lâmpadas, de ventiladores e de cadeiras. Estes dados foram representados graficamente com software de desenho computadorizado. 
Para determinação dos pontos de medição foram utilizados os procedimentos descritos na ANBT NBR 15215-4:2003 que considera o comprimento, a largura do compartimento e a altura da superfície de trabalho até a altura das luminárias das salas, para definir a posição e a quantidade de pontos de medição. As posições dos pontos foram registradas em plantas baixas.

Com os pontos de medições definidos foram feitas medições de intensidade luminosa utilizando um luxímetro TES 1332A sobre cada um deles. No momento das medições o luxímetro foi posicionado sobre as carteiras dos alunos, simulando a altura de trabalho do ambiente. Posteriormente os dados de intensidade luminosa coletados foram utilizados para determinação da iluminância. Todas as leituras foram feitas no período noturno sem a interferência de luz natural.

Na última fase, calculou-se utilizando o Método dos Lúmens ${ }^{7}$ a quantidade de luminárias e lâmpadas necessárias para alcançar a iluminância recomentada pela ANBT NBR ISO/CIE 8995-1:2013 para salas de aulas noturnas e de educação de adultos. Os resultados dos cálculos foram utilizados para elaboração da proposta de intervenção, que foi representada através de uma planta de teto refletido.

\subsection{MAPEAMENTO DAS SALAS DE AULA}

O objeto de estudos dessa pesquisa é uma escola pública localizada na zona urbana do município de Nova Venécia que atua com aulas noturnas. Todas as salas apresentam aproximadamente as mesmas dimensões e layout. A quantidade de salas analisadas foi definida por amostragem. Foram selecionadas 10 salas de aula de um total de 19 salas. As dimensões e do layout das salas foram registrados através de croquis e desenhos computacionais feitos no software AUTOCAD (2018). Para cada sala foram elaboradas: planta baixa com layout (Figura 1B), planta de teto refletido (Figura 1A) e planta com a locação dos pontos para medição (Figuras 1C).

Todas possuem em comum a cor do piso amarelo escuro e paredes em amarelo claro com a presença de detalhes em cinza escuro (rodapés, pilares aparentes e rodameios ${ }^{8}$ ). $\mathrm{O}$ teto, na cor branca, se constitui em uma laje de concreto e há a presença de uma viga aparente, também na cor branca com aproximadamente $50 \mathrm{~cm}$ de altura. Há cortinas nas janelas na cor cinza claro e nude. As janelas são de vidro e possuem acabamento em alumínio na cor verde escuro. As cadeiras possuem encosto, assento e prancheta em polipropileno azul. O quadro é na cor branca com bordas de madeira para utilização de pincel atômico.

Todas as salas apresentam uma única saída pela lateral, a qual consiste em uma porta de madeira envernizada com detalhes em cinza escuro e um visor em vidro transparente.

\footnotetext{
${ }^{7}$ O Método dos Lúmens tem como objetivo "[...] determinar o número de luminárias necessárias para se produzir uma determinada luminância em uma área e a base é o fluxo médio." (SANTOS, 2013, p. 30).

${ }^{8}$ Faixa de proteção à meia altura entre o piso e o teto.
} 
Com relação ao sistema de iluminação artificial, todas possuem 4 luminárias de sobrepor (Figura 1A) sem refletor e dois ventiladores de teto. As salas de 01 a 05 possuem lâmpadas de LED e as salas de 09 a 13 apresentam dois tipos diferentes de luminárias, sendo estas do modelo Luz do Dia e Luz do dia Especial, ambas fluorescentes. A ABNT NBR 15215-4:2003 define os procedimentos e quantidade de pontos de medição por ambiente para avaliação da iluminância. Para a realização das medições foi utilizado um luxímetro digital, marca TES, modelo TES 1332A, na escala de 2000 lux. O equipamento possui uma amplitude de escala entre 0 e 200.000 lux e sua precisão é de $0,5 \%$. As medições com o aparelho foram realizadas no período entre às 18 horas e 22 horas, desconsiderando a iluminação natural e a presença de alunos. Os procedimentos metodológicos utilizados para mensuração da iluminância estão descritos na ABNT NBR ISO/CIE 8995-1:2013. 


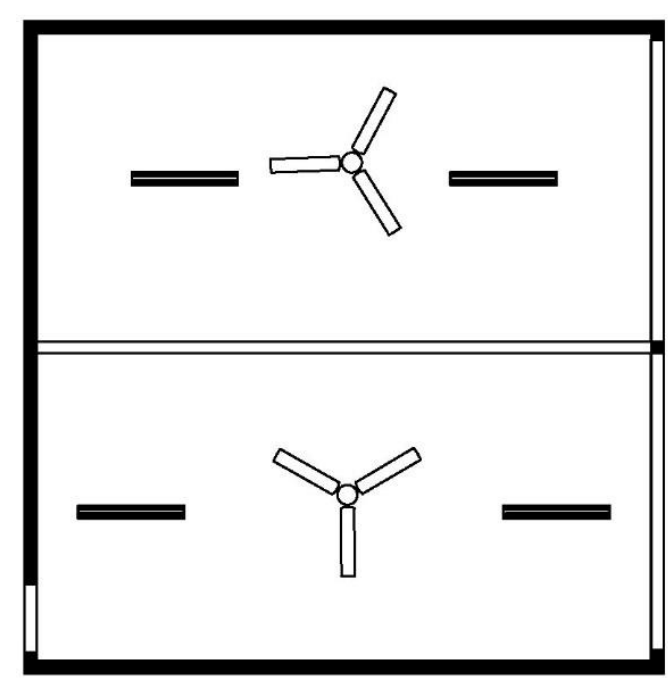

A
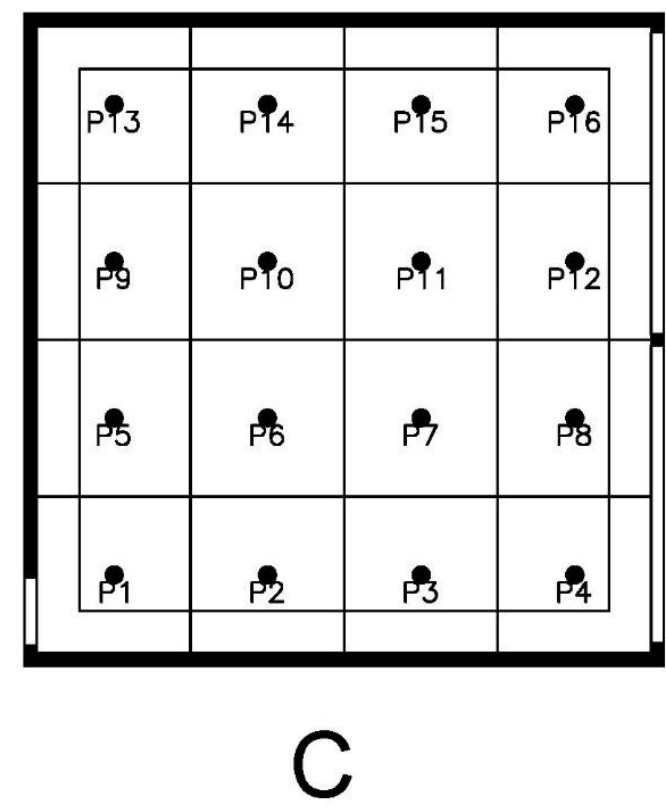

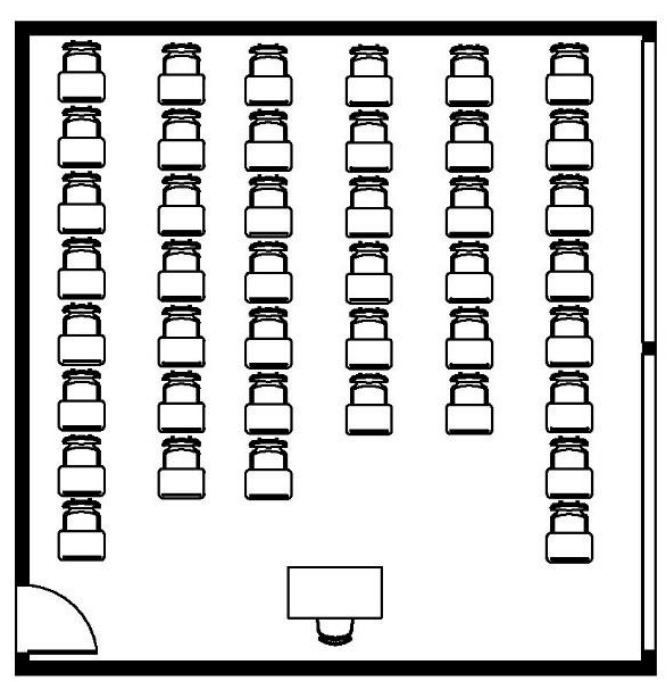

B

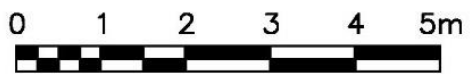

Figura 1: Modelo de mapeamento das salas

Fonte: Arquivo pessoal (2017)

Utilizou-se para dimensionar a iluminação dos ambientes o método dos lumens, também conhecido como método do fluxo luminoso (Creder, 2007, p. 163). Este método tem por objetivo "determinar o número de luminárias necessárias para se produzir uma determinada luminância em uma área e a base é o fluxo médio" (SANTOS, 2013, p. 30). Para determinação do nível de iluminância utilizou-se a 
ABNT NBR ISO/CIE 8995-1:2013-Iluminação de Ambientes (interiores) de Trabalho. Segundo a norma, em salas onde a atividade desenvolvida exige menor acuidade visual como salas estudos linguísticos, brinquedotecas e salas de aula comuns é necessária uma iluminância de no mínimo 300 lux. Em ambientes onde a atividade desenvolvida exige maior acuidade visual como salas de artesanato, uso do computador e laboratórios é necessária uma iluminância mínima de 500 lux. E especificamente para salas de aulas noturnas e de educação de adultos, como as salas de aulas objetos de estudos desta pesquisa, a iluminância mínima é de 500 lux. A norma também define que o limite de ofuscamento unificado (UGRL) e o Índice de reprodução de cor mínimo (Ra) sejam, respectivamente, de $19 \%$ e de $80 \%$ para salas de aulas noturnas.

\section{ANÁLISE E INTERPRETAÇÃO DOS DADOS}

Após a etapa de coleta dos dados, os mesmos foram organizados na Tabela 1.

Tabela 1 - Dados coletados nas salas de aula analisadas

\begin{tabular}{|c|c|c|c|c|c|c|}
\hline \multirow[t]{2}{*}{ Sala } & \multirow{2}{*}{$\begin{array}{l}\text { Área Interna da } \\
\quad \text { Sala }\left(\mathbf{m}^{2}\right)\end{array}$} & \multirow{2}{*}{$\begin{array}{l}\text { Quantidade de } \\
\text { Pontos }\end{array}$} & \multicolumn{3}{|c|}{ Leitura } & \multirow{2}{*}{$\begin{array}{c}\text { Média prevista pela } \\
\text { ABNT }\end{array}$} \\
\hline & & & $\begin{array}{l}\text { Máx. } \\
\text { (lux) }\end{array}$ & $\begin{array}{l}\text { Mín. } \\
\text { (lux) }\end{array}$ & $\begin{array}{c}\text { Média das } \\
\text { salas }\end{array}$ & \\
\hline 1 & 53,62 & 16 & 133 & 93 & 113,00 & 500 \\
\hline 2 & 51,86 & 16 & 128 & 78 & 112,06 & 500 \\
\hline 3 & 51,48 & 16 & 129 & 89 & 109,88 & 500 \\
\hline 4 & 52,67 & 16 & 126 & 87 & 112,25 & 500 \\
\hline 5 & 53,77 & 16 & 135 & 78 & 113,56 & 500 \\
\hline 9 & 52,76 & 16 & 191 & 124 & 156,81 & 500 \\
\hline 10 & 52,55 & 16 & 180 & 106 & 148,44 & 500 \\
\hline 11 & 53,24 & 16 & 165 & 113 & 145,12 & 500 \\
\hline 12 & 53,32 & 16 & 169 & 92 & 132,06 & 500 \\
\hline 13 & 53.69 & 16 & 177 & 109 & 145,31 & 500 \\
\hline
\end{tabular}

Fonte: Arquivo pessoal (2017)

Através da análise da Tabela 1 verificou-se que: 
- Nenhuma das 10 salas analisadas atingiu o valor mínimo estabelecido pela ABNT NBR ISO/CIE 8995-1:2013 de 500 lux;

- O menor valor obtido foi $78 \mathrm{Lux}$, que corresponde a 15,6\% do valor ideal; O maior valor obtido foi 191 Lux que corresponde 38,2\% do valor ideal.-Esses valores indicam que a iluminação nestes ambientes não está satisfatória para as atividades desenvolvidas. Na realização de suas atividades, os usuários desses ambientes (geralmente alunos que trabalham no período diurno e professores que trabalham em mais de um turno), estão sujeitos a dificuldades no aprendizado, dispersão, cansaço visual, devido ao esforço adicional provocado pelas sombras nos cadernos e livros, e este esforço prolongado pode desencadear problemas de visão.

- Observou-se ainda, que as salas 09, 10,11, 12 e 13, obtiveram uma média de iluminância mais elevada que as demais salas, devido a substituição das luminárias com lâmpadas fluorescentes por um modelo que usa lâmpadas de LED, que possuem uma intensidade luminosa maior que as lâmpadas fluorescentes.

- Das 160 medições de iluminância coletadas, 13,75\% delas alcançaram iluminância entre 0 e 100 lux, que representa 1/5 do valor ideal de 500 lux que a norma ABNT NBR ISO/CIE 8995-1:2013 estabelece. Já 86,25\% dos pontos coletados atingiram entre 100 a 200 lux, o que representa 2/5 do que a norma julga adequado.

- Percebeu-se também que em 50\% das salas analisadas, os quatro pontos com menores medições estão localizados na lateral onde se encontram as janelas das salas e em $80 \%$ das salas esses quatro pontos estão entre os cinco menores valores.

Todas as salas, apresentam cortinas de cores escuras (marrom e cinza) em suas janelas; o que explica o fato de valores tão baixos nas medições próximas a elas. Isso confirma que os tons mais escuros influenciam na iluminância e iluminação dos ambientes, pois segundo Almeida (2016, p.6): "As cores claras absorvem menos a luz e a refletem com maior intensidade, já as cores escuras absorvem a luz e não a reflete de volta para o ambiente.

Na Figura 2 é possível observar a diferença das médias, dos pontos coletados, das salas de aulas em comparação com o valor ideal da média de salas de aulas noturnas de 500 lux.

Figura 2 - Relação entre a iluminância média das salas e a iluminância prevista na a ABNT NBR ISO/CIE 8995-1:2013 


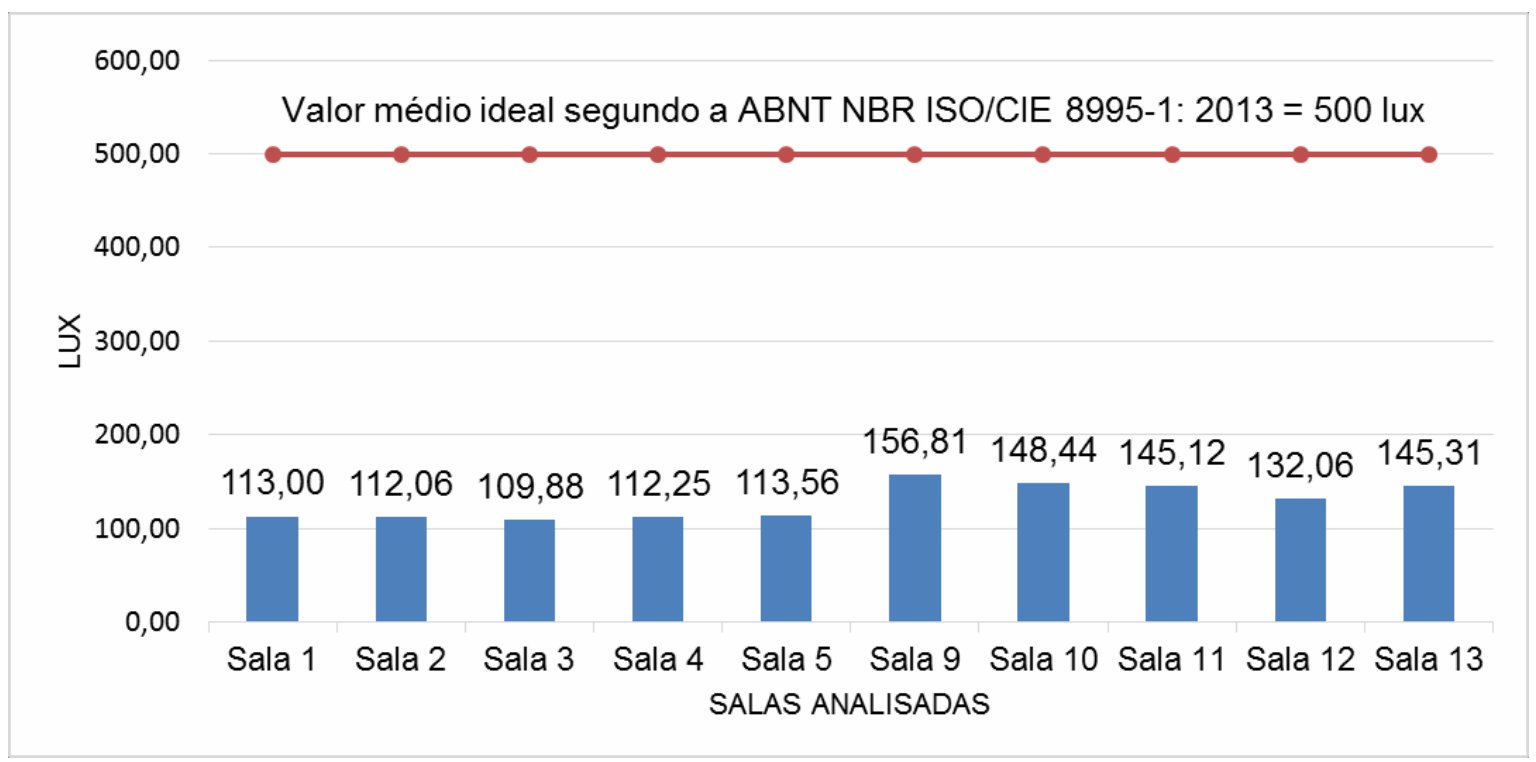

Fonte: Arquivo pessoal (2017)

Como pode ser observado na Figura 2, em todas as salas de aula a diferença entre esses valores é preocupante.

\subsection{PROPOSTA DE INTERVENÇÃO}

A proposta de intervenção foi feita com base em cálculos que determinam a quantidade de luminárias e de lâmpadas necessárias para atingir os valores de iluminâncias recomendados pela norma e consequentemente, ter-se uma iluminação adequada. Tais cálculos foram feitos pelo método dos lumens, também conhecido como método do fluxo luminoso.

Devido à padronização das salas (com dimensões parecidas e layout idêntico), foi selecionada uma das salas como objeto para esta etapa. A sala escolhida foi a sala 02 visto que apresentou valores de iluminância maiores.

No desenvolvimento da proposta foram realizados os seguintes procedimentos: a) determinação do nível de iluminância; b) escolha do tipo de luminária; c) determinação do índice local; d) determinação do coeficiente de utilização da luminária; e) determinação do fator de depreciação/manutenção da luminária; f) cálculo do fluxo luminoso total; g) cálculo do número de luminárias; h) espaçamento das luminárias. Aplicou-se as determinações da norma ABNT NBR ISO/CIE 8995-1:2013, e utilizou-se o método dos lumens (Creder, 2007).

Os resultados dos cálculos indicam a utilização de 12 luminárias com duas lâmpadas. Para facilitar a visualização das intervenções foi elaborada uma planta de teto refletido com as instalações originais (Figura 3) e outra com a proposta de intervenção (Figura 4). 

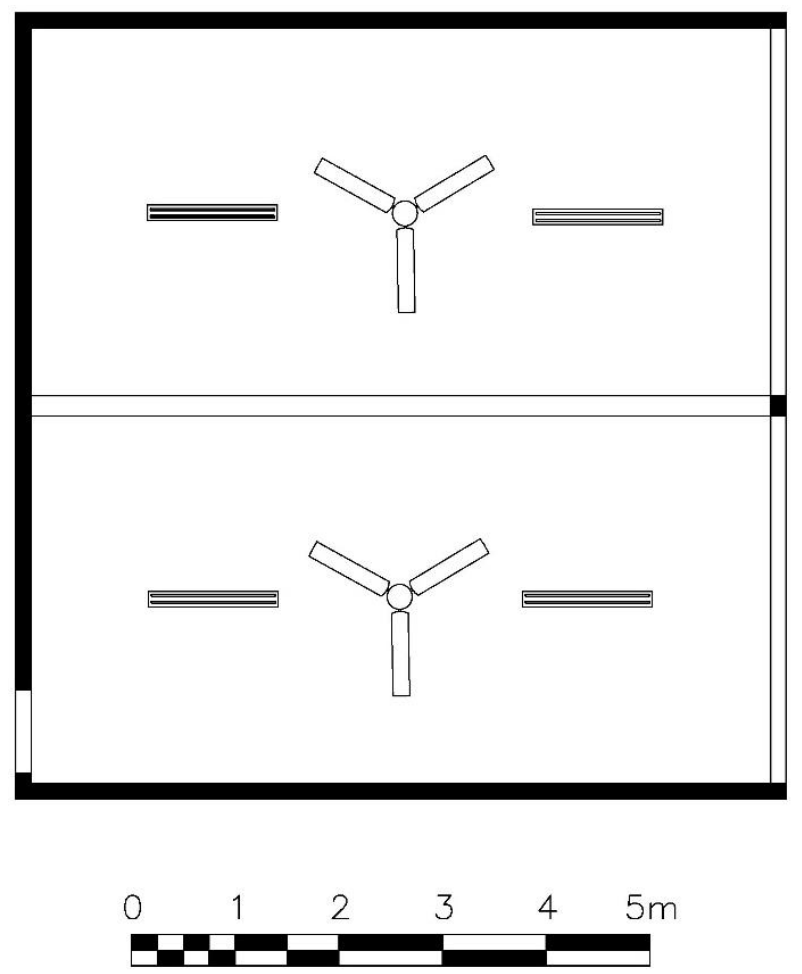

Figura 3: Planta de teto refletido da Sala 02 (instalações originais)

Fonte: Arquivo pessoal (2017)
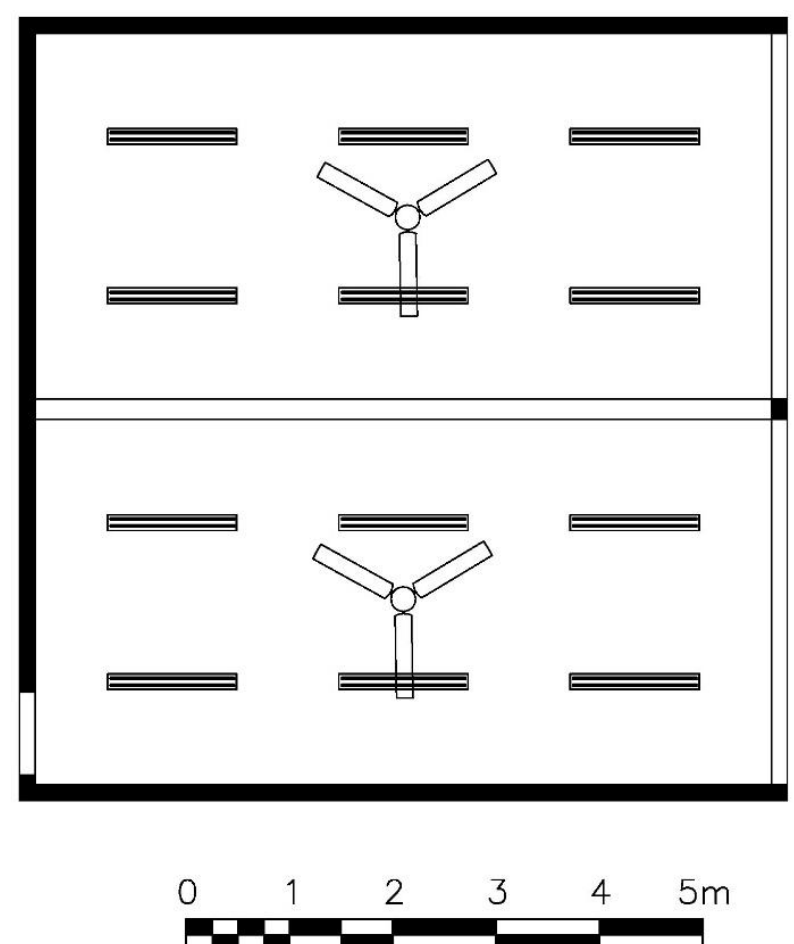

Figura 4: Planta de teto refletido da Sala 02 (proposta de intervenção)

Fonte: Arquivo pessoal (2017)

Na Figura 3 temos a representação das quatro luminárias e dois ventiladores existentes. Na Figura 4 temos a proposta calculada baseada na norma vigente. Para adequação desta sala, será necessário, 
portanto, aumentar de 4 para 12 o número de luminárias instaladas. E de 8 para 24 o número de lâmpadas.

\section{CONCLUSÕES}

Considerando que a iluminação influencia diretamente no conforto visual dos alunos e consequentemente no processo ensino-aprendizagem, e que muitas vezes o projeto luminotécnico é pouco valorizado em projetos escolares, trabalhos como esse são de suma importância para identificar deficiências na iluminação de salas de aulas.

A partir da análise da iluminância média das salas analisadas pôde-se constatar que nenhuma das salas atende ao valor mínimo de iluminância recomendado pela ABNT NBR ISO/CIE 8995-1:2013 para salas aulas noturnas e de educação de adultos. O maior valor de iluminância média encontrado nas salas de aulas analisadas representa apenas 31,36\% da iluminância recomentada pela norma.

As cores utilizadas em elementos como as cortinas influenciaram nos valores de iluminância, uma vez que elementos de cores escuras absorvem mais energia luminosa que elementos de cores claras. Além disso, as luminárias utilizadas no arranjo lumínico não contribuem para uma boa distribuição da luz o que pode ter influenciado nos baixos valores de iluminância média encontrados.

Deste modo, é importante que na concepção de uma edificação as condições de iluminação sejam consideradas e que o projeto luminotécnico seja pautado em variáveis como: o tipo de atividade desenvolvida em cada ambiente, a altura das superfícies de trabalho, a acuidade visual dos seus usuários, a distribuição da luz no ambiente, etc.

Espera-se que a presente pesquisa contribua para as discussões acerca da importância do projeto luminotécnico e do conforto visual em edificações escolares e que a intervenção proposta nesse trabalho possa ser usada pela escola objeto de estudo como um norteador para futuras intervenções nas instalações lumínicas.

\section{REFERÊNCIAS}

AGUIAR, João Carlos Rodrigues, coord. Manual de iluminação. Rio de Janeiro: PROCEL, 2011. $64 \mathrm{p}$.

AGUIAR, Victor; BUENO-BARTHOLOMEI, Carolina Lotufo. Conforto lumínico no ambiente escolar: níveis e iluminância em escolas públicas de Álvares Machado - SP. In: XV ENTAC ENCONTRO NACIONAL DE TECNOLOGIA DO AMBIENTE CONSTRUÍDO, 2014. Maceió AL. Anais... p.73-82.

ALMEIDA, Luzia Augusta Ribeiro. Iluminação natural e artificial no design de interiores. Revista Especialize, Aracaju, p.2-14, set. 2016. Disponível em: <file:///C:/Users/Cliente/

Desktop/augusta-ribeiro-1141713.pdf>. Acesso em: 27 out. 2017. 
ASSOCIAÇÃO BRASILEIRA DE NORMAS TÉCNICAS. NBR 15215: Iluminação natural Parte 4: verificação experimental das condições de iluminação interna de edificações - método de medição. Rio de Janeiro, ABNT, 2003.

NBR ISO/CIE 8995: Iluminação de ambientes de trabalho - Parte 1: interior. Rio de Janeiro: ABNT, 2013.

AUTOCAD. Versão 2018. [S.I.]: Autodesk, 2018.

BARKMANN, Claus; WESSOLOWSKI, Nino; SCHULTE-MARKWORT, Michael. Applicability and efficacy of variable light in schools. Revista physiology and behavior, v. 105, p. 621-627, fev. 2012. Disponível em: <https://www.sciencedirect.com/journal/physiology-and-behavior/ articles-in-press>. Acesso em: 16 outubro de 2018

BRASIL. Ministério da Educação. Fundo de Fortalecimento da Escola. Diretoria de Programas Especiais. Manual para adequação de prédios escolares. $1^{\mathrm{a}}$ ed. Brasília: MEC.

2006. Disponível em: <ftp://ftp.fnde.gov.br/web/fundescola/publicacoes_manuais_tecnicos/ manual_adequa cao_predios_escolares.pdf>. Acesso em: 25 maio 2017.

Ministério da Educação. Fundo de Fortalecimento da Escola. Espaços educativos. ensino fundamental. Subsídios para elaboração de projetos e Adequação de edificações escolares. $1^{\mathrm{a}}$ ed. Brasília: MEC. 2002. Disponível em: <http://www.dominiopublico.gov.br/download/texto/ me000575.pdf >. Acesso em: 25 maio 2017.

Ministério da Educação. Secretaria de Educação Básica. Parâmetros básicos de infraestrutura para instituições de educação infantil. $1^{\text {a }}$ ed. Brasília: MEC/SEB. 2006. Disponível em: 〈http://portal.mec.gov.br/seb/arquivos/pdf/Educinf/miolo_infraestr.pdf〉. Acesso em: 25 maio 2017.

CREDER, Hélio. Instalações elétricas. 15. ed. Rio de Janeiro: LTC - Livros Técnicos e Científicos Editora S.a., 2007. 428p.

DUTRA, Luciano; LAMBERTS, Robert; PEREIRA, Fernando O. Eficiência energética na arquitetura. $3^{\mathrm{a}}$ ed. Rio de Janeiro: ELETROBRAS/PROCEL, 2014.

HYBINER, Juliana Mara. Análise da iluminação em salas de aulas de escolas da rede de ensino pública das superintendências regionais de ensino de Juiz de Fora, Ponte Nova e Ubá, MG. 2015. 147f. Dissertação (Magister Scientiae) Programa de Pós-Graduação em Arquitetura e Urbanismo, Universidade Federal de Viçosa, Viçosa, 2015.

MONTEOLIVA, Juan Manuel et al. Study of attentional performance in children in classrooms with different lighting conditions. Revista CES Psicol, vol.9, n.2, pp.68-79. 2016.

PAIS, Aida Maria Garcia. Condições de iluminação em ambiente de escritório: Influência no conforto visual. 2011. 1 v. Dissertação (Mestrado) - Curso de Ergonomia na Segurança no Trabalho, Universidade Técnica de Lisboa - Faculdade de Motricidade Humana, Lisboa, 2011. Disponível em: <https://www.repository.utl.pt/bitstream/10400.5/3048/1/Microsoft Word - Tese dEFINITIVA2.pdf $>$. Acesso em: 24 maio 2017.

PROCEL. Manual de iluminação. Rio de Janeiro: PROCEL/ELETROBRAS, 2011. Disponível em: <http://www.mme.gov.br/documents/10584/1985241/MANUAL\%20DE\%20ILUMINA CAO\%20\%20PROCEL_EPP\%20-AGOSTO\%202011.pdf> Acesso em: 27 abr. 2017. 
SANTOS, Felipe Albino da Silva. Eficiência energética na indústria e luminotécnica. 2013. 70 f. Monografia (Especialização) - Curso de Engenharia Elétrica, Universidade Federal do Rio de Janeiro, Rio de Janeiro, 2013.

SILVA, Camila Moreno de Camargo e. A importância da iluminação no ambiente escolar. Revista Especialize, Goiânia, v. 8, p.1-17, dez. 2014. Semestral. Disponível em: <https://www.ipog.edu.br/ revista-especialize-online/edicao-n8 2014/?setarParametros=true\&pagingPage=4\&>. Acesso em: 25 maio 2017. 